\title{
DOI: 10.7596/taksad.v6i4.1172
}

Citation: Voloshina, L., Kondakov, V., Kopeikina, E., Tretyakov, A., \& Galimskaya, O. (2017). Investigation of Relationships in the Children's Team in the Process of Sports Gaming. Journal of History Culture and Art Research, 6(4), 277-285. doi:http://dx.doi.org/10.7596/taksad.v6i4.1172

\section{Investigation of Relationships in the Children's Team in the Process of Sports Gaming}

\author{
Lyudmila N. Voloshina ${ }^{1}$, Victor L. Kondakov ${ }^{2}$ \\ Evgeniya N. Kopeikina ${ }^{3}$, Andrey A. Tretyakov ${ }^{4}$, Olga G. Galimskaya ${ }^{5}$
}

\begin{abstract}
The article presents the results of studying the children's readiness (in the age of 5-7 years old) to interact with peers and adults in the elementary sports and gaming activities. The study was carried out within the framework of the pilot program of the Russian Academy of Education, based on the pre-school educational institutions in the city of Belgorod. To study the relationship in the children's team we used observation, sociometric technique, and diagnostic game situation. The analysis of results obtained showed the presence of problems of readiness to interact with peers and the formation of a communicative component of social experience in children in the age of 5-7 years old. Namely: insufficient level of children's independence, limited ideas about the possibility of using the sports and gaming activities in their own experience, low level of social and normative behavior. The results of the study confirmed the data previously presented in the publications on the growth in the number of preschool children not capable to interpersonal interaction.
\end{abstract}

Keywords: Preschool child, Socialization, Social experience, Interaction, Social and communicative development, Sports and gaming activities.

\footnotetext{
${ }^{1}$ Belgorod State University L. N. Voloshina, Belgorod State National Research University, Pobeda St. 85, Belgorod, Russia, 308015. E-mail: voloshina_l@bsu.edu.ru

${ }^{2}$ Belgorod State University L. N. Voloshina, Belgorod State National Research University, Pobeda St. 85, Belgorod, Russia, 308015.

${ }^{3}$ Belgorod State University L. N. Voloshina, Belgorod State National Research University, Pobeda St. 85, Belgorod, Russia, 308015.

${ }^{4}$ Belgorod State University L. N. Voloshina, Belgorod State National Research University, Pobeda St. 85, Belgorod, Russia, 308015.

${ }^{5}$ Belgorod State University L. N. Voloshina, Belgorod State National Research University, Pobeda St. 85, Belgorod, Russia, 308015.
} 


\section{Introduction}

The development of social experience, certain roles, rules of behavior, the child's entry into the social environment and adaptation to it actively occurs during childhood. In the course of children's activities, knowledge of social ties is expanded; the social experience of a growing person is enriched. A child learns not only to understand, but also to evaluate social phenomena, behavior of other children and adults. This confirms the child's readiness to interact with peers and adults. At the same time, we understand the readiness for interaction as the individual's active state, setting for a certain behavior, mobilization of forces to perform the task (Big Psychological Encyclopedia, 2015).

Modern children in the age of 5-7 years old the previous generations outstrip their peers in development in many respects, but as it is shown by the analysis of modern studies, there are significant problems in the field of their social and communicative development. $25 \%$ of graduates of pre-school establishments have a low level of readiness for interaction, inability to take a common goal, to agree on the activity methods, there is helplessness in making independent decisions in the simplest life situations (Feldstein, 2013). In the long term, this can adversely affect the children's adaptation in the period of mastering the new social role of a pupil.

In our opinion, the potential of sports-gambling activities is not sufficiently used in the solution of this problem in the pre-school education practice. The works of a number of authors (Voloshina and Kurilova, 2015; Glazyrina, 1999; Tretiak, 2006) note that the knowledge of cultural norms and rules of behavior in the sports games, knowledge of the methods of playing actions and playing roles, special game signals enables preschool children to communicate positively with the playing children during mastering the sports games, enriches the social experience of a child.

A number of scientific studies of foreign scientists (DeMarco, Zeisel, and Odom, 2014; Howie et al., 2014; Chelsey et al., 2017) also points to the problems associated with the fact that the child needs to acquire social experience and become a full member of society. A number of other specialists also indicate the need to use a wide range of universal means for the successful socialization of a growing person, the choice of which is determined by the requirements of society, social stratum and age (Larissa et al., 2017). According to these authors, the child's inclusion to the social norms is carried out in communication, play, cognition, in various activities in the main spheres of life activity (Howie et al., 2014). 
By basing on the current literature, the purpose of our study was to identify the readiness level of children in the age of 5-7 years old to interact in the process of mastering the sports and gaming activities.

\section{Materials and methods of study}

To determine the ability to coordinate their activities with peers, to adopt a common goal, to jointly plan the work, the ability to negotiate in the process of activity and to evaluate the results obtained, we applied a diagnostic situation with the use of mobile game "We will not say where we have been, but we will show what we have seen" (Voloshina and Kurilova, 2015). To study the interpersonal relations in the group of preschool children, we chose the selection situation "Give a postcard" (Scientific and Methodical Grant, 2010). Initiative, general semantic field of interaction, ability to accept and implement the rules were studied in the monitoring of children in the sports and gaming activities (Bateman, 2015; A Reference Book for Senior Teachers of Preschool Institutions, 2015; Pate et al., 2014; Theobald, 2016; Theobald and Danby, 2012). In assessing the readiness of senior preschool children to interact with their peers in the sports and gaming activities, the following criteria and indicators were taken as a benchmark.

High level - cooperation (7-10 points): preschool children have a sufficient amount of ideas about the cooperation rules. The process of children's activities is distinguished by consistency, ordering of actions. The general semantic field of interaction exists continuously. There is a sense of "we" expressed in functional reciprocity, harmonious combination of subject, practical, verbal and non-verbal acts in relation to each other in the course of all activities. The result of joint activities is understood and evaluated by children as an overall work result.

Intermediate level - fragmentary cooperation (4-6 points): visions of preschool children of the rules and methods of cooperation are incomplete, inaccurate, and insufficiently conscious. The joint actions are characterized by the adoption of a common goal by children, perception of the situation as a joint task situation in general. However, the activity process takes place in parallel. There is a presence of subjective standards in the task performance. The general technical criteria of work are not established between the participants. A single semantic field arises in fragments. The participants' regulation of each other's actions is intermittent, episodic. The preschool children are concerned about the action result, but they evaluate it from the position of individual contribution. 
Low level - inability to cooperate (1-3 points): children call single rules of cooperation. It is difficult to single out the rule in accordance with the task for them. There is no awareness of these visions of the rules, which is confirmed by the lack of attempts of their actual application in joint activities. The actions are characterized by inability to perceive the goal set in the situations as general, referring it only to oneself, without reference to the partner, or formal acceptance of the goal as general, but with projecting this goal to an individual action program in the process of fulfilling the task. The activity process of the participants runs in parallel. Each of them performs the task in individual logic and tempo. A common semantic field for cooperation does not arise. There is no regulation of each other's actions with the general progress of the work. There is no relation to the result as an overall work result.

\section{Study results and their discussion}

Analysis of the results of the game diagnostic technique "We will not say where we have been, but we will show what we have seen" indicates that only $24 \%$ of children in the experimental groups (12 children) and 18\% of children in the control groups ( 9 children) can work in teams, are set up positively for the performance of the collective task. We traced the partnership and equality in their activity. Children quietly listened to the task, coordinated their actions in selecting the story of the game situation scenario, negotiated on the choice of image methods, and were actively engaged in dialogue. Replicas had the nature of sentence ("let's get on the line"). When performing the task children also used the non-verbal communication means. The game situation was built quickly, in accordance with the plan, which indicates a sufficient level of cooperation development. In the course of all activities, the preschool children had the feeling of "we" in relation to each other.

Manifestations of children's cooperation with their peers in the game situation "We will not say where we have been, but we will show what we have seen" were expressed in different ways. In our opinion, they are related to the features of self-disclosure and self-fulfillment of the child. A significant part of children (42\% in the experimental and the control groups) observed the partner's actions and performed the action by sample (for example, Dasha K., responding to a question about how she performed the task, answered: "I watched what Roma was doing and repeated after him"). The semantic field appeared fragmentarily, when the children were discussing some elements of the game situation. But, basically, the activity process took place in parallel, the regulation of children's activities was carried out intermittently. Eventually, after disputes and mutual assistance, the given game situation "On the football field" was depicted. 
The low level of readiness for interaction was detected in 34\% of children in the experimental groups (17 children) and $40 \%$ of children in the control groups (20 children). Children performed the task at an individual pace and logic, not coordinating the actions with the partner. There was no management of the overall process of the task performance, which was showed by the result in the end - the game situations were not completed. Preschool children did not coordinate their actions. Everyone wanted to perform the actions independently, without negotiating with the team. When explaining how the child performed the task, many children said "I wanted so", "I liked being an "attacker" more".

Study of the statistical significance of the differences in the mean values obtained during the methodology procedure "We will not say where we have been, but we will show what we have seen" showed that the average value in the control groups was $4.06 \pm 0.25$, and in the experimental ones $-4.48 \pm 0.26$. The value of Student's t-criteria was 1.16 . This means that the differences between the results in the control groups and in the experimental groups are not statistically significant $(\mathrm{p}>0.05)$. At the same time, the critical value of Student's t-criteria $=$ 1.987 , with the significance level of $\alpha=0.05$, and the number of freedom degrees of $f=98$.

The results obtained in the course of the selection situation enable to conclude that none of the preschool children scored 6 or more selections ("stars") in the study group, and 24\% of children scored 3-5 selections ("adopted"). Almost half of the children (49\%) had 1-2 selections ("unaccepted"). 36\% of children did not receive a single selection. These children often display incontinence of their emotions, which provokes conflict situations in communicating with peers. They need the teacher's help, his support. The selections of preschool children were conditioned by the subjective attitude towards children - "like to play" or "do not like to play", their experience of communication and interaction with their peers.

Study of the statistical significance of the differences in the mean values obtained in the course of methodology procedure "Give a postcard" showed that the average value in the control groups was $3.56 \pm 0.17$, and in the experimental ones - 3.98 \pm 0.21 . The value of Student's t-criteria was 1.55 . This means that the differences between the results in the control groups and in the experimental groups are not statistically significant ( $>>0.05)$. At the same time, the critical value of Student's t-criteria $=1.987$, with the significance level of $\alpha=0.05$, and the number of freedom degrees of $\mathrm{f}=98$.

Observation of the children's actions in the process of sports and gaming activities and comparison with the results obtained in other assignments showed that preschool children knew cultural norms and rules of behavior, were guided by the generally accepted values, but did not always adhered to them and observed them when participating in mobile and sports 
games. Only 23\% of children constantly provide their own help to peers and younger children in the process of playing. $77 \%$ of children have difficulties in working together when coordinating their actions during the game; do not always restrain the expression of their emotions. They can assess a specific situation, but do not always make the right decision and provide assistance at the peer's request.

Study of the statistical significance of the differences in the mean values obtained in the course of monitoring the children's actions in the process of elementary sports and gambling activities showed that the average value in the control groups was $4.06 \pm 0.25$, and in the experimental ones $-4.52 \pm 0.25$. The value of Student's t-criteria was 1.22 . This means that the differences between the results in the control groups and in the experimental groups are not statistically significant $(\mathrm{p}>0.05)$. At the same time, the critical value of Student's t-criteria $=$ 1.987 , with the significance level of $\alpha=0.05$, and the number of freedom degrees of $f=98$.

The analysis of the obtained results confirms the presence of problems of readiness to interact with peers, noted earlier in the studies of A.V. Tretiak (2006), D.I. Feldstein (2013). Thus, $38 \%$ of children have such problems as insufficient level of independence in the organization of elementary sports and gambling activities, lack of action regulation, there is limited representation of children about the possibilities of using the sports games in their own experience (Tretiak, 2006; Voloshina and Demicheva, 2014; Voloshina et al., 2016). The low level of manifestation of the socially-normative behavior by children in the sports games makes it difficult to organize teamwork.

A study of the statistical significance of differences in the mean values obtained during the above methods showed that the differences between the results of the control groups and the experimental groups were not statistically significant. That is, preschool children have similar indicators at the beginning of the experiment both in the control groups and in the experimental groups.

In our opinion, it is possible to increase the effectiveness of impact of sports games on the social and communicative development, if we include communicative minutes, conversations, problem situations, game rituals and reflections in the physical culture classes. In regime moments - special communication games for reflection and correction of communication problems.

\section{Summary}

The theoretical analysis and generalization of literary data on the problem of readiness of older preschool children to interact with peers and adults in the sports and gaming activities, which we have conducted, proves the existence of a problem situation. 
As noted in the works of many scientists, the search for the most appropriate socialization means of the child's personality should be based on an analysis of characteristics and criteria that reflect the various aspects of activity of a growing person.

The experts in the field of child development suggest that the ability to coordinate their activities with peers, to adopt a common goal, to jointly plan work, and the ability to negotiate in the course of activities are important issues in the child's personality socialization. These are the experiment results of the European scientists.

In turn, the social and communicative experience makes it possible to build a solid foundation for supporting the developing personality of a child.

The sports and gambling tools cover the expected characteristics and criteria of the social and communicative sphere of preschool children as much as possible.

Based on the results of modern researches of Balsevich V.K., Komkov A.G. Krivolapchuk I.A., Lubysheva L.I. and our own research, we believe that the possibilities of elementary sports and gaming activity are not fully implemented in the tasks of socializing a child of preschool age.

\section{Conclusions}

1. An effective mean of forming the social and communicative sphere of preschool children, which provide both the age opportunities and individual needs of a growing person, are the game programs and physical education technologies that are used in the educational process of preschool institutions in Russia.

2. The sports games contain a wide range of tools to provide an impact not only on the development of the perceptually-motor, but also the social-communicative sphere of the child. The socio-communicative activity, arising in the initial development process of the sports games, makes it possible for the child to determine his position within the peers.

\section{References}

Bateman, A. (2015). Conversation analysis and early childhood education: The co-production of knowledge and relationships. Ashgate Publishing, Ltd.

Big Psychological Encyclopedia [An electronic resource]. - Access mode: http://onlineslovari.com/psihologicheskiy_slovar/page/gotovnost_k_deyst viyu.451 (21.09.2015) 
Chelsey, R. Schlechter; Richard, R. Rosenkranz; Bronwyn, S. Fees \& David, A. Dzewaltowski (2017). Preschool Daily Patterns of Physical Activity Driven by Location and Social Context. School health, 87 (3): 194-199.

DeMarco, A. C.; Zeisel, S. \& Odom, S. L. (2014). An evaluation of a program to increase physical activity for young children in child care. Early Education and Development, (26), 1-21. doi:10.1080/10409289.2014.932237

Feldstein, D. I. (2013). The world of the childhood in the modern world (problems and research problems): MPSU: Voronezh: MODEK.

Glazyrina, L. D. (1999). Physical culture - to preschool children. Advanced age: a grant for teachers preschool institutions. M.: Gumanit. Prod. VLADOS center.

Guidelines of Using the Educational Program of Preschool Education: A Reference Book for Senior Teachers of Preschool Institutions (2015). No.10. Pp. 9-18.

Howie, K.; Brewer, A.; Brown, W. H.; Pfeiffer, K. A.; Saunders, R. P. \& Pate, R. R. (2014). The 3-year evolution of a preschool physical activity intervention through a collaborative partnership between research interventionists and preschool teachers. Health Education Research, 29(3): 491-502.

Larissa, T.; Karin, A. P.; Marsha, D.; Harriet, G. Williams; William, H. Brown; Jennifer, R. O’Neill \& Russell, R. Pate (2017). Motor competence and characteristics within the preschool environment. Original Research Article Journal of Science and Medicine in Sport, Available online 24 January.

Monitoring in kindergarten, Scientific and methodical grant (2010). SPb.: CHILDHOOD-PRESS.

Pate, R. R.; O’Neill, J. R.; Brown, W. H.; McIver, K. L.; Howie, E. K. \& Dowda, M. (2014). Top ten research questions related to physical activity in preschool children. Research Quarterly for Exercise and Sport, (84), 448-455.

Serykh, L. V. \& Shinkareva, L. V. (2015). Problems and Prospects of Implementation of the Federal State Educational Standard in Preschool Educational Institutions of Belgorod Region // Fundamental Research (2), 40084012.

Theobald, M. \& Danby, S. (2012). «A problem of versions»: Laying down the law in the school playground. In S. Danby \& M. Theobald (Eds.), Disputes in everyday life: Social and moral orders of children and young people. New York: Emerald. 
Theobald, M. (2016). Achieving competence: The interactional features of children's storytelling. Childhood, 23(1), 87-104.

Tretiak A. V. (2006). Pedagogical conditions of formation of interaction of children of the advanced preschool age with peers in games with rules: Abstract of a thesis ... candidate of pedagogical sciences. - SPb.

Voloshina L. N.; Kondakov V. L. A.; Tretyakov A. A. \& Nikulina D. E. (2016). Regulation of physical activity of preschool children / International Journal of Pharmacy and Technology, 8(2), 14275-14282. URL: http://www.ijptonline.com/wp-content/uploads/2016/07/14275-14282.pdf.

Voloshina, L. N. \& Kurilova, T. V. (2015). Play on health! Physical training of children of 3-7 years: the program, abstracts of occupations, materials for conversations, a training technique in uneven-age groups: Ventana-Graf.

Voloshina, L. N. \& Demicheva, V. V. (2014). Design of training of future teachers for innovative activity in the conditions of a regional education system //Scientific result. Series: Pedagogics and psychology of education, 1(1), 5-13. 